\title{
NOVOS GÊNERO E ESPÉCIE DE SATYRINAE (LEPIDOPTERA, NYMPHALIDAE) DO SUDESTE BRASILEIRO
}

\author{
Heinz Ebert ${ }^{1}$ \\ Manoel Martins Dias ${ }^{2}$
}

\begin{abstract}
New genus and SpeCies of Satyrinae (Lepidoptera, Nymphalidae) FROM SOUTHERN BRAZIL. Euptychia paeon (Godart, 1824) (=Euptychia marmorata Butler, 1866) and Euptychia griseldis Weymer, 1911 are placed under Carminda gen.n. Carminda umuarama sp.n. is described. The studied specimens are from southern Brazil and adjacent areas of Paraguay and Argentina.

KEY WORDS. Lepidoptera, Nymphalidae, Satyrinae, Euptychia, Carminda.
\end{abstract}

Euptychia paeon (Godart, 1824) (=Euptychia marmorata Butler, 1866) e Euptychia griseldis Weymer, 1911 (Nymphalidae,Satyrinae) são espécies conhecidas das regiões sudeste e sul brasileiras, chegando a áreas limítrofes do Paraguai. E. griseldis foi registrada também em Misiones, Argentina. KIRBY (1871) referiu-se a E. paeon e E. marmorata como espécies distintas. WEYMER (1911), descreveu e ilustrou E. griseldis; ilustrou também E. paeon e E. marmorata, considerando esta última como uma forma de $E$. paeon. As ilustrações de Weymer são da face inferior das asas e não deixam dúvida sobre a identidade das duas espécies.Estas não foram mencionadas por FORSTER (1964), em cujos resultados muitas espécies até então incluidas em Euptychia Hübner, 1818, receberam novos gêneros. HAYWARD (1967) referiu-se a E. paeon e E. marmorata como espécies distintas; a ilustração (prancha 18, figura 9), designada $E$. paeon, representa na realidade $E$. griseldis. MiLlER (1968) referiu-se aos gêneros estabelecidos por FORSTER (1964) e respectivas espécies-tipo, mas não citou E. paeon e E. griseldis. D'ABRERA (1988) ilustrou as faces superior (macho) e inferior (fềmea) de E. paeon (citada com grafia errônea, "poeon"); a terceira ilustração, à direita da prancha, designada E. paeon, representa a face inferior de E. griseldis, macho. Brown (1992) referiu-se a $E$. paeon como espécie freqüente nas florestas da Serra do Japi; mencionou também que a lagarta alimenta-se de folhas de bambus. Recentemente, MiELKE (1994) citou E. paeon e E. griseldis em listagem de borboletas de Curitiba e arredores, Paraná.

No presente trabalho propõe-se para essas duas espécies um novo gênero, denominado Carminda, que homenageia a Dra. Carminda Cruz-Landim, eminente professora e pesquisadora da Universidade Estadual Paulista, Campus de Rio Claro. Descreve-se nesse gênero uma nova espécie: Carminda umuarama.

1) In memorian

2) Departamento de Ecologia e Biologia Evolutiva, Universidade Federal de São Carlos. Caixa Postal 676, 13565-905 São Carlos, São Paulo, Brasil. 


\section{MATERIAL E MÉTODOS}

O material examinado pertence às coleções entomológicas citadas a seguir, acompanhadas dos nomes de seus responsáveis e das siglas correspondentes; estas são mencionadas na relação do material.

Coleções examinadas: MZSP - Museu de Zoologia, Universidade de São Paulo (C. Costa); UFPR - Departamento de Zoologia, Universidade Federal do Paraná (O.H.H. Mielke); UFSCAR - Departamento de Ecologia e Biologia Evolutiva, Universidade Federal de São Carlos (M.M. Dias); UNICAMP - Departamento de Zoologia, Universidade Estadual de Campinas (K.S. Brown Jr.).

Para cada espécie é dada, em milímetros, a medida da margem costal da asa anterior, referente ao menor e ao maior exemplar de cada sexo. Na relação do material examinado de C. umuarama sp.n. estão incluídos todos os dados dos rótulos dos exemplares. Genitálias examinadas foram conservadas em pequenos tubos, imersas em glicerina; os tubos foram mantidos anexos aos respectivos exemplares. Asas diafanizadas foram mantidas secas, anexas aos respectivos exemplares.

\section{Carminda gen.n.}

Sexos semelhantes em coloração e desenho das asas. Fêmeas geralmente pouco maiores que os machos, com asa anterior mais larga. Margem externa da asa posterior denteada, expandida nas seguintes veias: $\mathrm{M}_{1}, \mathrm{M}_{2}, \mathrm{M}_{3}, \mathrm{CuA}_{1}, \mathrm{CuA}_{2}, 2 \mathrm{~A}$ (Fig. 41).

Face superior das asas castanho uniforme, com duas linhas marginais castanho-escuras; essas linhas podem ser alargadas, formando faixas estreitas, difusas ou não. Asa anterior com faixa estreita transversal castanho-escura, pós-discal, pouco aparente. Asa posterior com duas faixas estreitas transversais, pouco aparentes, onduladas irregularmente; a faixa mais externa junto ou próxima ao ápice da célula discal e a mais interna passando pela célula transversalmente; asa posterior com três pontos (ou máculas arredondadas) submarginais, castanho-escuros ou pretos, nem sempre nítidos.

Face inferior das asas com o mesmo desenho da face superior, porém, mais nítido. Pontos ou máculas submarginais evidentes. Asa posterior geralmente com quatro máculas pretas, arredondadas, submarginais, duas próximas ao ápice e duas próximas ao ângulo anal; essas máculas são circundadas por linha amarelada e cada uma tem na área preta, dois pontos argênteos, às vezes, reduzidos; asa anterior sobretudo castanha; asa posterior de coloração variável, com predominância de castanho, intercalado com áreas amareladas ou esbranquiçadas e em geral com pontuação fina, castanho-escura, dispersa ou em grupos.

\section{Carminda paeon (Godart, 1824), comb.n.}

Figs $1-7,25,28,30,42$

Satyrus paeon Godart, 1824: 490.

Euptychia marmorata Butler, 1866: 471, pl. 40, fig. 1.

Olho composto com cerdas muito curtas e dispersas; comprimento das cerdas 
aproximadamente igual ao triplo do diâmetro de um omatídio; distância entre as cerdas igual ou maior que o comprimento destas.

Asa anterior, margem costal: macho $16-20 \mathrm{~mm}$; fêmea $18-22 \mathrm{~mm}$.
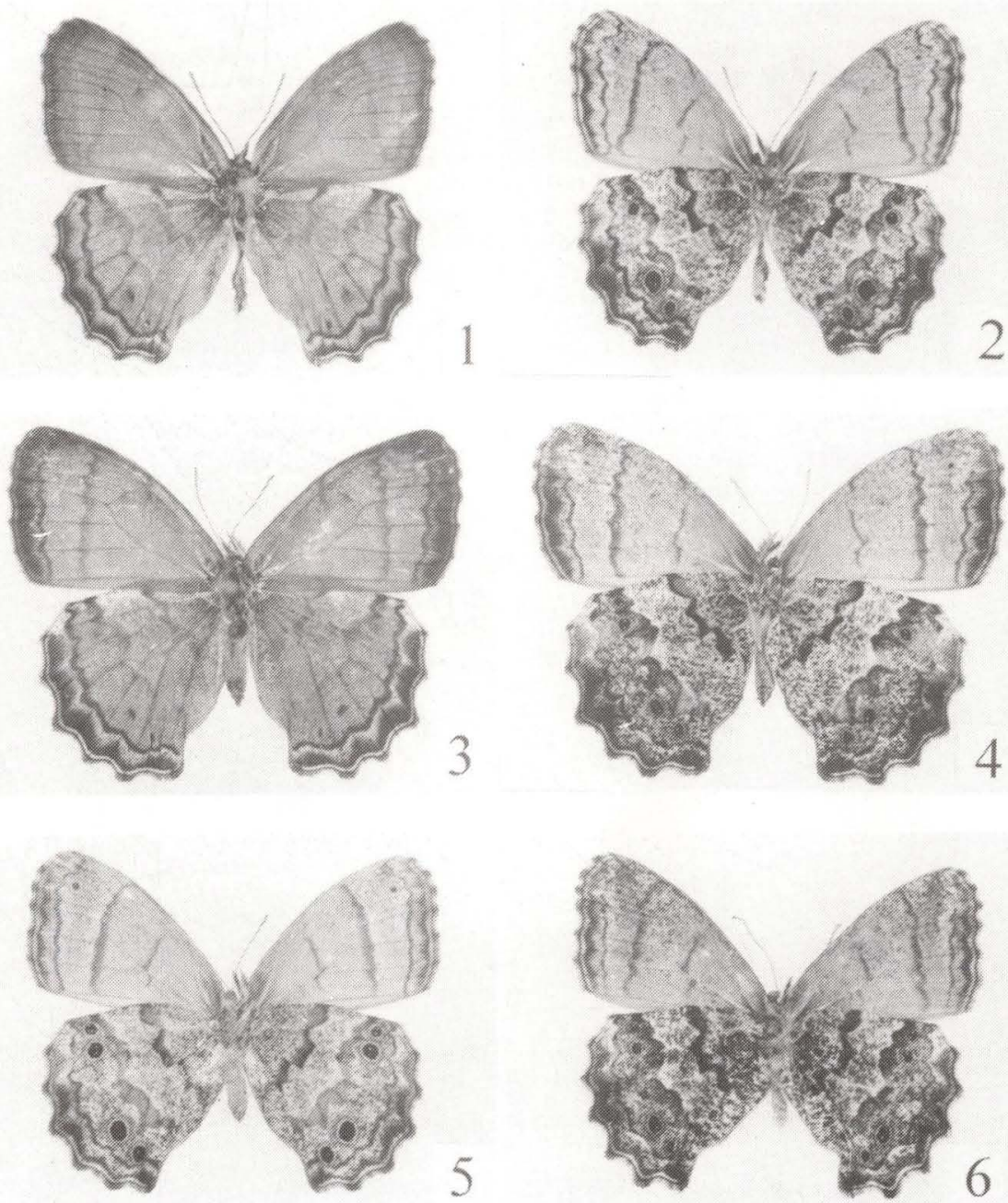

Figs 1-6. Carminda paeon. (1) Macho, Ciudad del Este (100km oeste), Paraguai; (2) idem, face inferior; (3) fêmea, Alexandra, Paraná; (4) idem, face inferior; (5) fêmea, Itatiaia, Rio de Janeiro, face inferior; (6) macho, São Bento do Sul, Santa Catarina, face inferior. 

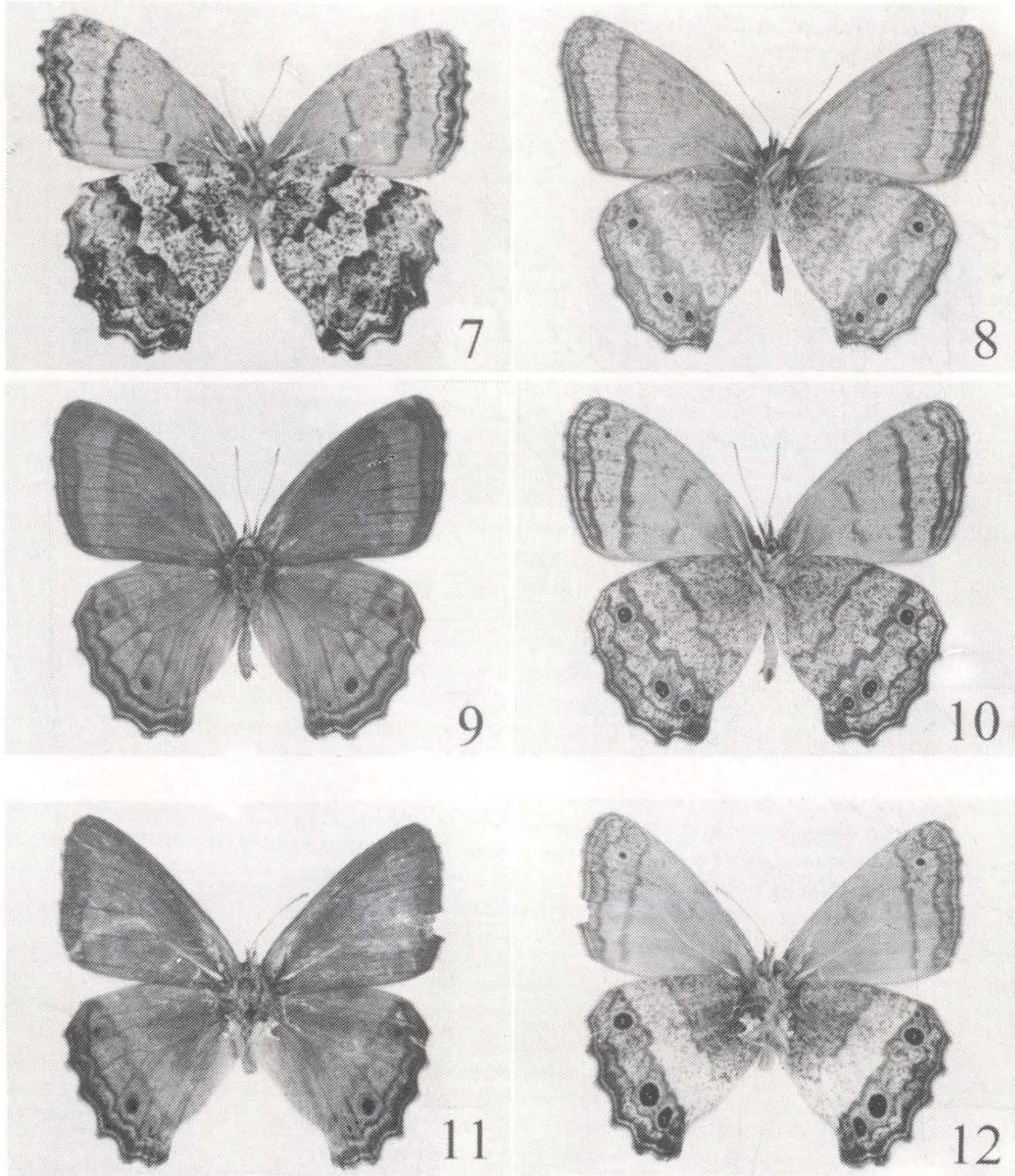

Figs 7-12. (7) Carminda paeon, macho, Santo Amaro, São Paulo, face inferior. (8-12) Carminda griseldis, macho. (8) Guarapuava, Paraná, face inferior; (9) São Carlos, São Paulo; (10) idem, face inferior; (11) Poços de Caldas, Minas Gerais; (12) idem, face inferior.

Face superior das asas castanho-uniforme; faixa castanho-escura na margem externa, mais larga na fêmea; lado interno dessa faixa geralmente difuso, acompanhado de linha castanho-escura, paralela à faixa. Asa anterior com faixa estreita transversal, castanho-escura, pós-discal, mais evidente na fêmea. Margem costal da asa posterior geralmente com pequena área esbranquiçada entre as bases das duas faixas transversais onduladas; a base de cada faixa é castanho-escura. $\mathrm{Na}$ asa 
posterior, próximo ao ângulo anal, internamente à linha castanha submarginal, um ou dois pontos (ou máculas arredondadas) castanho-escuros.
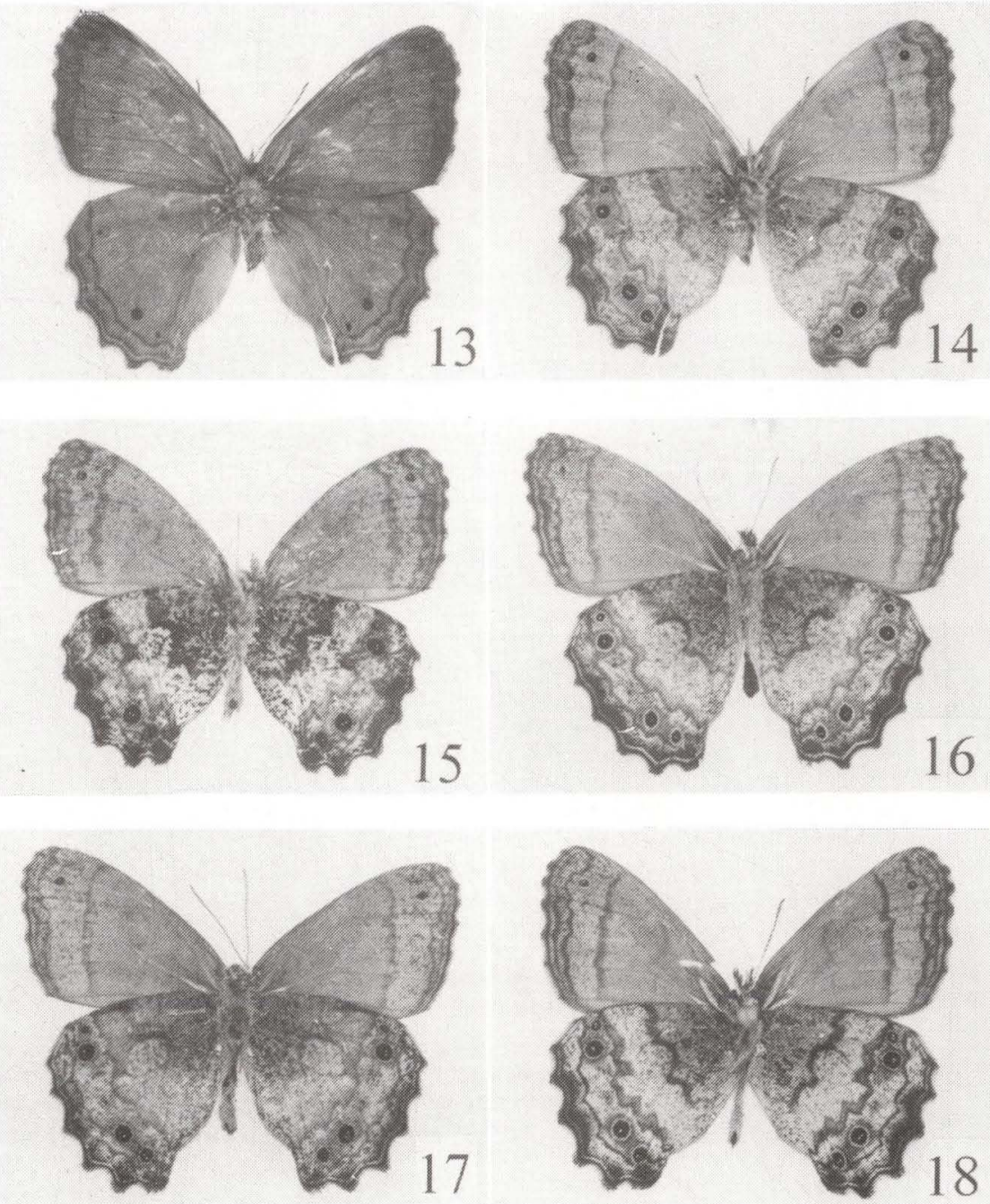

Figs 13-18. Carminda griseldis, macho. (13) São Bento do Sul, Santa Catarina; (14) idem, face inferior; (15) Serra da Bocaina, São Paulo; (16) Joinvile, Santa Catarina; (17) Joinvile, Santa Catarina; (18) Fênix, Paraná. 

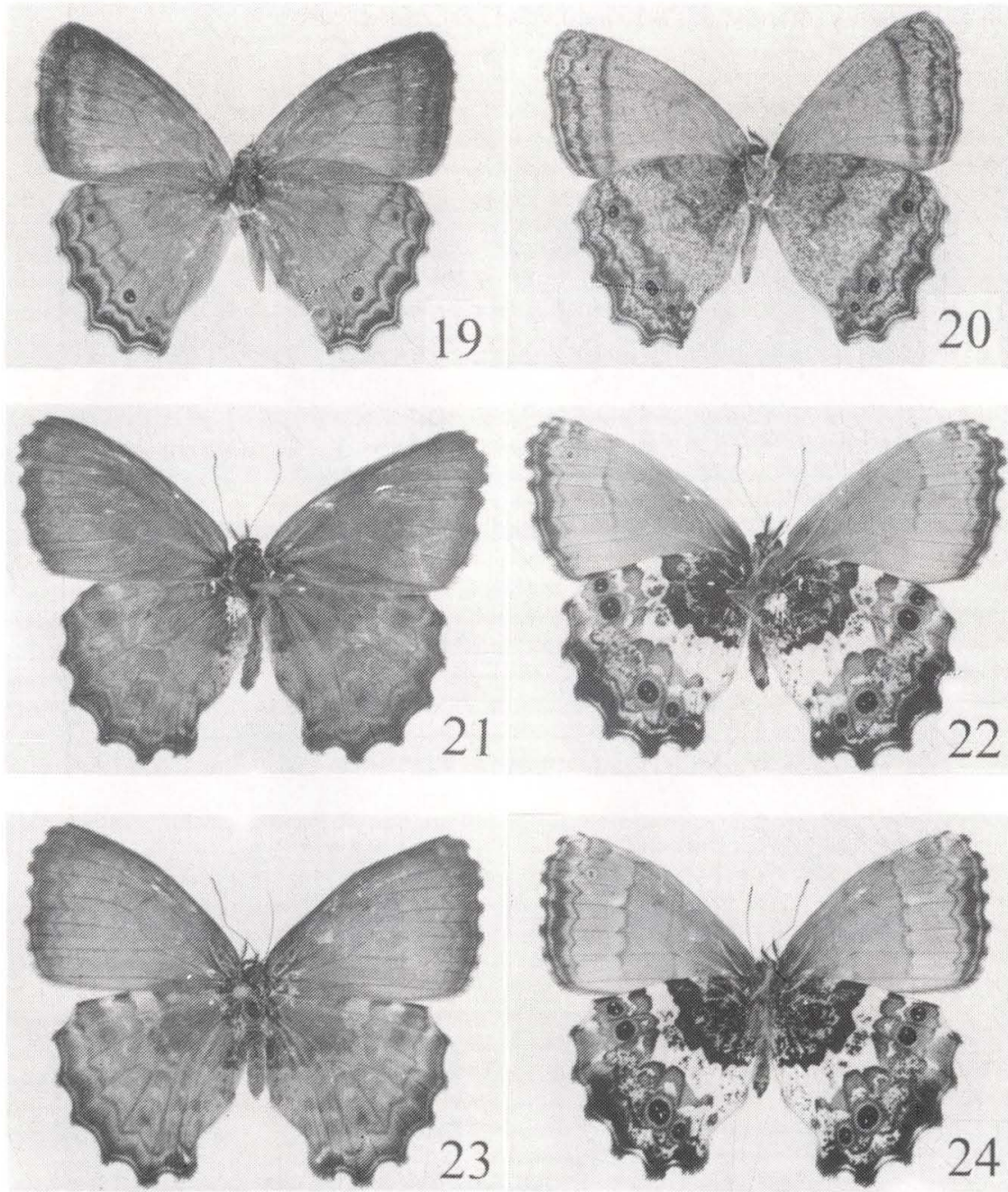

Figs 19-24. (19-20) Carminda griseldis, fêmea. (19) Joinvile, Santa Catarina; (20) idem, face inferior. (21-24) Carminda umuarama. (21) Holótipo macho, Umuarama, Campos do Jordão, São Paulo; (22) idem, face inferior; (23) parátipo fêmea, Itatiaia, Rio de Janeiro; (24) idem, face inferior.

Face inferior das asas de coloração castanha, variável na asa posterior. Asa anterior com faixa marginal geralmente larga, castanho-escura, difusa do lado interno, e paralela a essa faixa, linha das mesma cor, submarginal; internamente a essa linha, próximo ao ápice da asa, ponto (ou mácula)preto, às vezes, quase ausente; faixa pós-discal castanho-escura e internamente à esta, faixa mais estreita e menos 
definida, com a mesma cor, passando pela célula discal transversalmente. Asa posterior com faixas transversais onduladas, variando de coloração entre castanhoescuro, castanho-claro e ocráceo; asa geralmente castanho-clara, com áreas castanho-escuras ou ocráceas, variadamente dispostas entre as faixas onduladas ou externamente a estas. Asa posterior e metade distal da asa anterior, com pontuação fina, castanha, dispersa irregularmente, mais densa na asa posterior.

Genitália masculina. Comprimento das valvas quase o triplo da largura (Fig. 30 ); extremidade distal das valvas arredondada, com dentes voltados para o lado interno (Fig. 28); unco afilado na base e alargado na metade distal (Fig. 25).

Material examinado (51 machos e 136 fêmeas). BrasiL, Espirito Santo: Santa Tereza, 1 fềmea (UFPR), 4 fêmeas (UNICAMP); Alto Rio Jucú, Km 75 Vitória-Manhuacú, 1 fềmea (UNICAMP). Rio de Janeiro: Rio de Janeiro, 1 macho e 3 fêmeas (UFPR); 1 macho e 1 fềmea (UNICAMP); Itatiaia, 4 machos e 10 fêmeas (UFPR); 1 macho e 1 fêmea (UNICAMP); Rio de Janeiro (Bico do Papagaio, Serra da Tijuca), 1 fêmea (UFPR); Petrópolis, 1 fềmea (UFPR); 1 macho e 3 fêmeas (UNICAMP); Petrópolis (Parque São Vicente), 2 fêmeas (UFPR). Petrópolis (Independência), 1 fêmea (UFPR); Teresópolis (Serra dos Órgãos), 2 fêmeas (UFPR); Rio de Janeiro (Jacarepaguá, Três Rios), 1 macho (UFPR); Imbariê (Serra dos Órgãos), 11 fêmeas (UFPR); Xerém (Serra do Tinguá), 1 fềmea (UFPR); Km 27 Rio de Janeiro-Teresópolis, 1 macho (UNICAMP); Angra dos Reis (Jussaral), 1 fềmea (UFPR). Minas Gerais: Santa Bárbara (Serra do Caraça), 1 macho e 1 fềmea (UFPR); Juiz de Fora (Rio Paraibuna), 1 macho e 3 fềmeas (UFPR); Barbacena (Serra da Mantiqueira), 2 machos e 2 fêmeas (UFPR); Barbacena (Km 289, Rio Belo), 2 fềmeas (UNICAMP); Ouro Preto (Fazenda Barcellos), 2 machos (UFPR); Poços de Caldas, 3 machos e 5 fêmeas (UFPR); Cambuquira, 1 macho e 1 fềmea (UFPR). São Paulo: São Paulo, 3 machos e 2 fêmeas (MZSP); São Paulo (Ipiranga), 2 fêmeas (UFPR); São Paulo (Água Funda), 1 macho (MZSP); São Paulo (Serra da Cantareira), 1 macho e 4 fêmeas (UFPR); Paranapiacaba (Alto da Serra), 1 fêmea (MZSP); Apiaí (Serra de Paranapiacaba), 2 fêmeas (UFPR); Jundiaí (Serra do Japi), 1 fêmea (UNICAMP); Rio Claro, 5 fềmeas (UFPR); Caraguatatuba, 3 fềmeas (UFPR); Ubatuba, 1 fềmea (UFPR); Salesópolis (Estação Biológica de Boracéia) 7 fêmeas (MZSP); São Paulo (Santo Amaro), 1 macho (UFSCAR); São Vicente, 1 macho (UFSCAR); Cananéia (Ilha do Cardoso) 1 fêmea (UFSCAR); Itirapina, 1 macho e 1 fêmea (UFSCAR). Paraná: Curitiba, 1 fêmea (UNICAMP); Curitiba (Cascatinha), 1 macho (UFPR), 1 fêmea (UFSCAR); Colombo, 1 macho e 1 fêmea (UFPR), 1 fêmea (UFSCAR); Guarapuava, 2 machos e 2 fêmeas (UFPR); Guarapuava (Santa Clara), 1 fêmea (UFPR); Guarapuava (Candoi), 1 fêmea (UFPR); Tijucas do Sul (Vossoroca), 2 fêmeas (UFPR); Ponta Grossa, 2 machos (UFPR); Ponta Grossa (Pedreira), 1 fêmea (UFPR); Palmas, 1 fềmea (UFPR); Morretes, 1 macho (UFPR); Morretes (Marumbi), 1 fêmea (UFPR); Alto Amparo, 1 fêmea (UFPR); Rolândia (Rio Tibagi), 1 fềmea (UFPR); Alexandra, 1 fêmea (UFSCAR). Santa Catarina: São Bento do Sul, 4 machos e 11 fêmeas (UFPR), 1 fềmea (MZSP); Joinvile, 1 macho e 2 fêmeas (UFPR), 4 fềmeas (MZSP); Timbó, 1 fềmea (MZSP); Seara, 4 fêmeas (UFPR), 1 macho (MZSP). Curitibanos, 1 macho e 1 fêmea (UFPR); Lages, 1 macho (UFPR). Rio Grande do Sul: 1 fêmea (MZSP); Taquary, 1 macho 

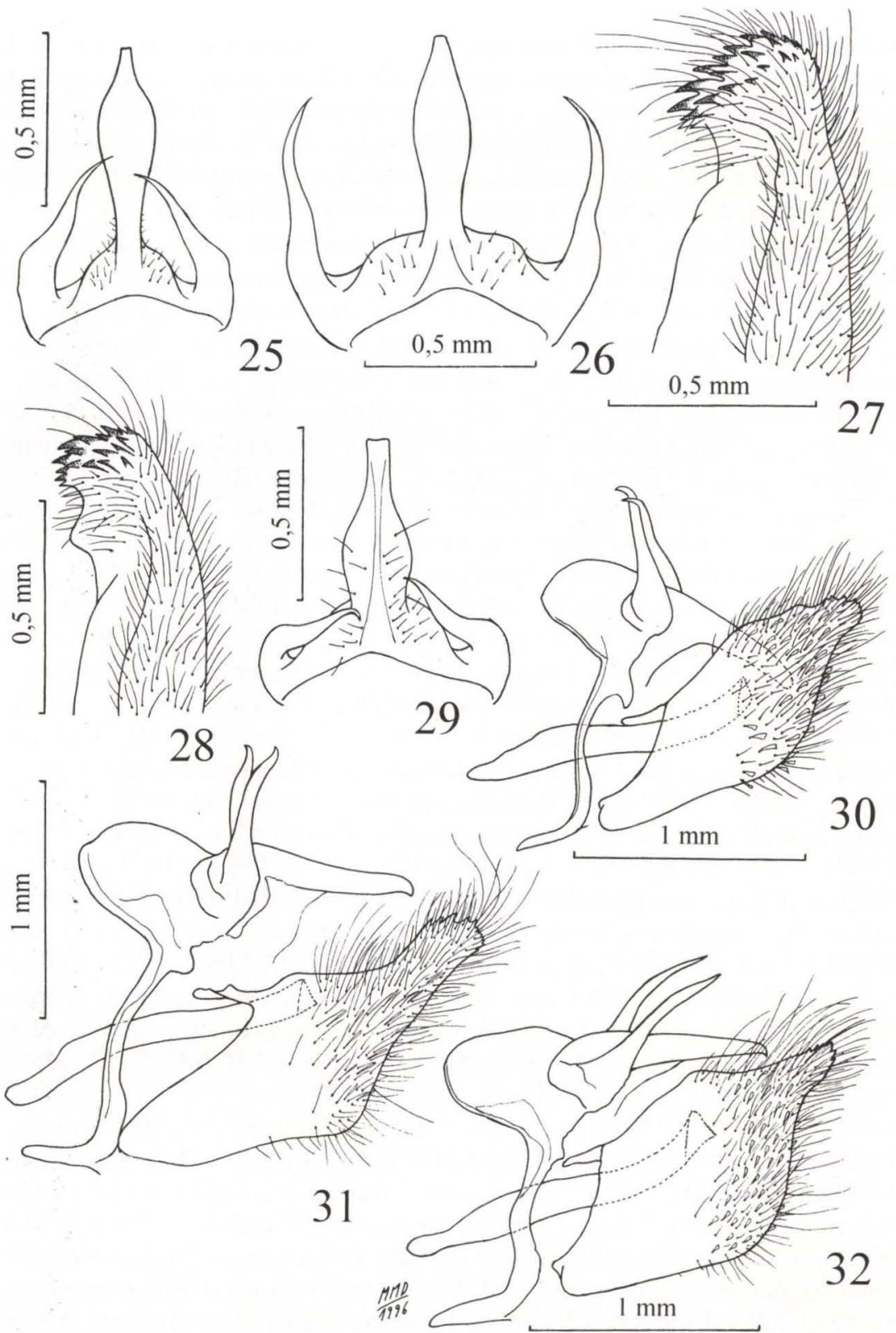

28

Figs 25-32. Genitália masculina. Carminda paeon, Joinvile, Santa Catarina: (25) unco, vista dorsal; (28) extremidade da valva, vista ventral-interna; (30) genitália em vista lateral. Carminda griseldis, Joinvile, Santa Catarina: (29) unco, vista dorsal; (31) genitália em vista lateral. Carminda umuarama, parátipo, Itatiaia, Rio de Janeiro: (26) unco, vista dorsal; (27) extremidade da valva, vista ventral-interna; (32) genitália em vista lateral. 
(MZSP); Pelotas, 1 macho e 2 fềmeas (UFPR); Campo Novo, 1 fềmea (UFPR); Tenente Portela (Parque Florestal Estadual Turvo), 1 macho (UFSCAR), 1 fêmea (UFPR). Gramado (Serra Geral) 2 machos e 1 fêmea (UFPR); Gramado-Canela (Serra Geral), 2 machos e 1 fêmea (UFPR). PARAGUAI, Alto Paraná: $100 \mathrm{~km}$ oeste de Ciudad del Este, 1 macho (UFPR); Guaira: Villarica (Colonia Sudetia), 1 fêmea (UFPR).

\section{Carminda griseldis (Weymer, 1911), comb.n.}

Figs $8-20,29,31,33-40,42$

Euptychia griseldis Weymer, 1911: 211, pl. 48d.

Olho composto com cerdas longas e densas; comprimento das cerdas aproximadamente igual a quatorze vezes o diâmetro de um omatídio; distância entre as cerdas muito menor que o comprimento destas.

Asa anterior, margem costal: macho 17-22mm; fêmea 18-27mm.

Face superior das asas castanho-uniforme. Linha castanho-escura na margem externa da asa anterior; na margem externa da asa posterior, faixa castanho-escura, com lado interno difuso; em ambas as asas, linha e faixa acompanhadas no lado interno de faixa estreita, paralela, castanho-escura. Asa anterior com faixa estreita transversal, pós-discal, castanho-escura, mais evidente na fêmea. Margem costal da asa posterior totalmente castanha. Asa anterior com ponto castanho-escuro, subapical, fracamente marcado ou ausente. Asa posterior com pontos (ou máculas arredondadas) internos à faixa estreita castanha sub-marginal, com a seguinte disposição: um próximo ao ápice; um ou dois próximos ao ângulo anal.

Face inferior das asas de coloração castanha, variável na asa posterior. Asa anterior com linha castanho-escura na margem externa, pouco alargada e difusa em alguns indivíduos; do lado interno desta e paralela, faixa estreita da mesma cor; internamente à essa faixa, próximo ao ápice da asa, ponto (ou mácula) preto, às vezes ausente; faixa pós-discal castanho-escura e internamente a esta, faixa mais estreita e menos definida (ou quase ausente) passando pela célula discal transversalmente. Asa posterior com faixas transversais onduladas castanhas ou ocráceas; coloração da asa geralmente castanho-clara, com áreas castanho-escuras, ocráceas ou esbranquiçadas, dispostas entre as faixas onduladas ou externamente a estas; alguns indivíduos (Fig. 12) com predominância de coloração branca entre as faixas onduladas.Pontuação castanha, dispersa irregularmente nas asas, como citado para C. paeon.

Genitália masculina. Comprimento das valvas duas vezes e meia a largura (Fig. 31); extremidade distal das valvas afilada e curva para dentro, com dentes dispostos irregularmente no ápice e na margem dorsal, variáveis em forma e disposição; próximo à extremidade da valva, saliência arredondada na margem dorsal, com dentes (Figs 35-40); unco bastante alargado na base (Fig. 33) ou moderadamente alargado (Figs 29, 34).

Material examinado (76 machos e 107 fềmeas). BRASIL. Espirito Santo: Santa Teresa, 1 macho (UFPR). Rio de Janeiro: Itatiaia, 1 macho e 10 fêmeas (UFPR), 1 fềmea (UFPR); Petrópolis, 3 fềmeas (UFPR); Nova Friburgo (Muri), 1 

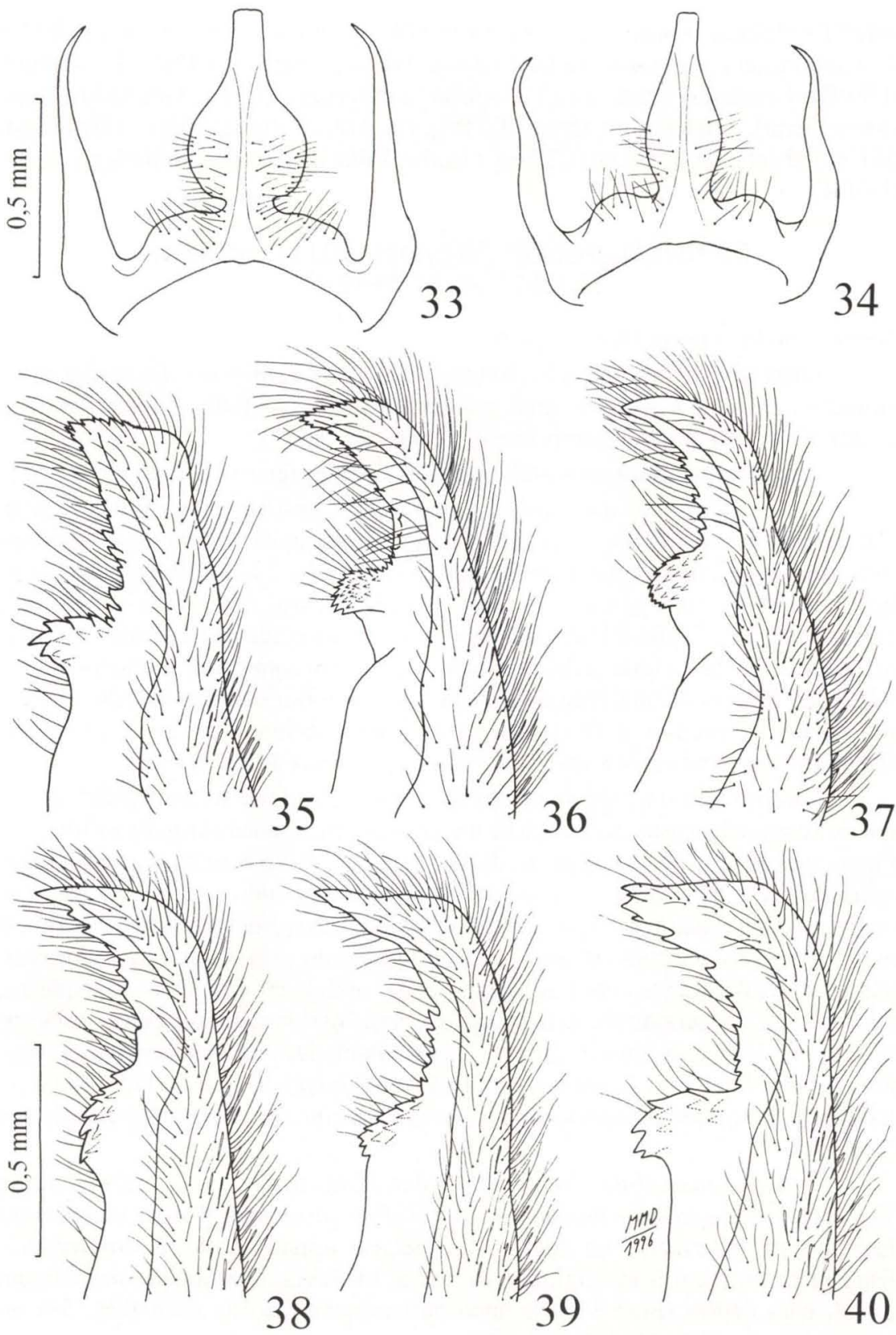

Figs 33-40. Genitália masculina, Carminda griseldis. Unco, vista dorsal: (33) Poços de Caldas, Minas Gerais; (34) São Bento do Sul, Santa Catarina. Extremidade da valva, vista ventral-interna: (35) Joinvile, Santa Catarina; (36) Poços de Caldas, Minas Gerais; (39) Camanducaia, Minas Gerais; $(37,38,40)$ São Bento do Sul, Santa Catarina. 

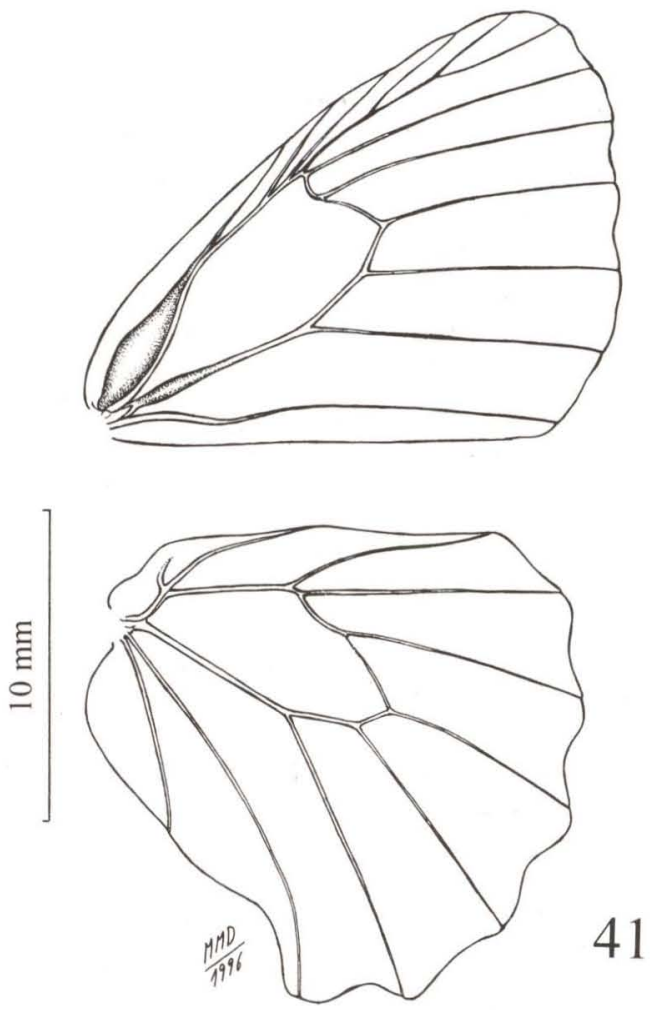

Fig. 41. Venação de Carminda umuarama, fêmea.

fêmea (UFPR); Teresópolis, 1 macho e 1 fêmea (UFPR), 1 macho e 1 fêmea (UNICAMP). Minas Gerais: Santa Bárbara (Serra do Caraça), 1 macho e 2 fêmeas (UFPR); Barbacena (Serra da Mantiqueira), 1 macho e 3 fêmeas (UFPR); Poços de Caldas, 1 macho e 4 fềmeas (UFPR); Cambuquira, 3 machos e 4 fêmeas (UFPR). Camanducaia (Monte Verde), 1 machio (UFPR). São Paulo: São Paulo, 1 fêmea (UFPR), 2 machos (MZSP); São Paulo (Ipiranga), 1 macho e 1 fêmea (MZSP); São Paulo (Água Funda), 1 macho (MZSP); Paranapiacaba (Alto da Serra), 1 macho (MZSP); Jundiaí (Serra do Japi), 2 machos e 1 fêmea (UNICAMP); Salesópolis (Estação Biológica de Boracéia), 1 macho e 2 fêmeas (UFPR), 1 machos e 7 fềmeas (MZSP); Campos do Jordão, 1 macho e 4 fêmeas (UFPR), 1 macho (UNICAMP). Campos do Jordão (Umuarama), 1 fêmea (UFPR); São Carlos, 1 macho e 3 fêmeas (UFSCAR); Anhembi (Fazenda Barreiro Rico), 2 fêmeas (UFPR), 1 fêmea (MZSP); Serra da Bocaina, 1 macho e 1 fêmea (UFPR); Bananal (Serra da Bocaina), 1 macho (UFPR); São Paulo (Serra da Cantareira) 1 macho (UFPR); São Bernardo do Campo, 1 macho (MZSP); Pariquera-Açu, 1 fêmea (MZSP). Paraná: Curitiba, 1 macho (UFPR); Guarapuava, 2 machos e 1 fêmea (UFPR); Lapa, 1 fêmea (MZSP); Foz do Iguaçu, 2 machos e 6 fêmeas (UFPR); Fênix, 2 machos (UFPR); Alexandra, 1 fềmea (UFPR); Cerro Azul, 1 fềmea (UFPR); São Luiz do Purunã, 2 machos 
(UFPR); Rolândia (Rio Tibagi), 1 macho e 4 fêmeas (UFPR); Cascavel, 1 macho (UFPR); General Carneiro, 1 macho (UFPR); Morretes (Pilão de Pedra), 1 macho (UFPR); Tijucas do Sul (Vossoroca), 1 macho (UFSCAR); Tijucas do Sul (Rincão), 1 macho (UFPR); Castro, 1 fêmea (UFPR); Guarapuava (Santa Clara), 1 macho (UFSCAR). Santa Catarina: São Bento do Sul, 11 machos e 10 fềmeas (UFPR); São Bento do Sul (Rio Vermelho), 2 fêmeas (UFPR); Joinvile, 6 machos e 10 fêmeas (UFPR), 1 macho e 1 fêmea (MZSP); Timbó, 1 macho (MZSP); Seara, 2 machos e 1 fêmea (UFPR); Lages, 1 macho e 2 fềmeas (UFPR); São Joaquim-Lages, 1 fềmea (UFPR); Lages (Parque Pedras Brancas), 1 macho (UFPR); São Joaquim (Mantiqueira), 1 macho e 1 fềmea (UFPR); Bituva-Mafra, 1 fêmea (UFPR); Taió (Rio Taió), 1 fêmea (UFPR); Santa Cecília (Campo Alto), 1 macho e 1 fêmea (UFPR). Rio Grande do Sul: Guarani, 1 fềmea (UFPR);. Guarani-Luiz Gonzaga, 1 macho (UFPR); Cambará de Sul (Serra Geral, Itaimbezinho), 1 macho e 1 fêmea (UFPR); Tenente Portela (Parque Florestal Estadual Turvo), 3 machos (UFPR). PARAGUAI, Alto Paraná: General Dias (Itaquiri), 3 machos e 1 fêmeas (UFPR). Guaira: Villarica, 1 fềmea (UFPR). Presidente Hayes: Colonia Carlos Pfannl, 1 fêmea (UFPR). ARGENTINA, Misiones: 1 fêmea (UFPR).

\section{Carminda umuarama sp.n.}

Figs $21-24,26,27,32,41,42$

Olho composto com cerdas curtas e moderadamente densas; comprimento das cerdas aproximadamente igual a oito vezes o diâmetro de um omatídio; distância entre as cerdas igual ou menor que o comprimento destas.

Asa anterior, margem costal: macho $18-20 \mathrm{~mm}$, fêmea $21-23 \mathrm{~mm}$.

Face superior das asas castanho-uniforme, mais escuro que nas duas espécies precedentes; faixa castanho-escura na margem externa, difusa, mais larga na fêmea; lado interno dessa faixa acompanhado por linha paralela, castanho-escura, ondulada. Linha pós-discal pouco aparente ou ausente na asa anterior. Margem costal da asa posterior com pequena área esbranquiçada entre as bases das duas faixas transversais onduladas; a base de cada faixa é castanho-escura. Ângulo anal da asa posterior castanho-escuro, com pequeno traço oblíquo, esbranquiçado; próximo ao ângulo anal, internamente à linha castanha sub-marginal, ponto (ou mácula arredondada) castanho-escuro.

Face inferior da asa anterior castanho-clara. Faixa marginal castanho-escura, e pàralela ao lado interno desta, linha ondulada da mesma cor; internamente à essa linha, próximo ao ápice da asa, ponto (ou mácula) preto, circundado por linha amarelada. Faixa estreita, pós-discal castanho-escura; nos machos, menos definida, da margem costal à veia $\mathrm{CuA} 2$; nas fêmeas, geralmente da margem costal à veia 2 A, sendo mais nítida e ondulada. Internamente à essa faixa, linha da mesma cor, pouco definida (ou ausente), passando pela célula transversalmente.

Face inferior da asa posterior, com faixa transversal ondulada interna castanho-escura e faixa ondulada externa, castanho-amarelada ou ocrácea. Base da asa, até a faixa ondulada interna, densamente pontuada de castanho-escuro de forma irregular e intercalada com áreas cinzento-azuladas, que podem ser bastante redu- 

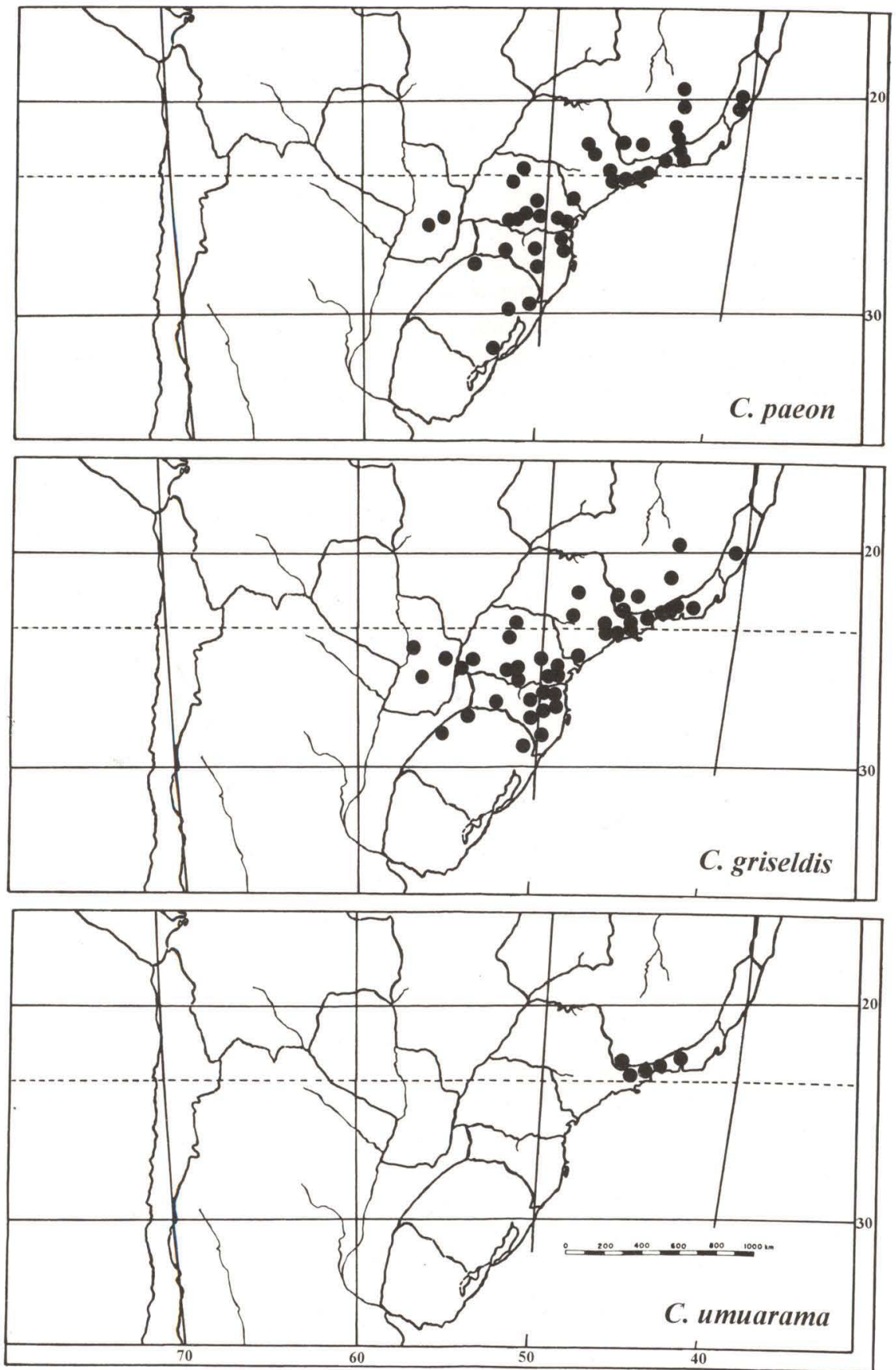

Fig. 42. Distribuição geográfica das espécies de Carminda. 
zidas. Faixas onduladas mais próximas entre si, junto à margem costal. Área entre as faixas onduladas, branca-amarelada, exceto junto à margem interna onde é branca, levemente azulada (essa variação de tonalidade observável apenas em exemplares novos); faixa branca, com pontuação castanho-escura, fina, na margem interna e concentrada irregularmente na célula discal e próximoà esta, sobre pequena área cinzento-azulada, irregular. Entre a faixa ondulada externa e a margem externa da asa, coloração castanho-clara ou ocrácea, com área irregular cinzento-azulada, pontuada de castanho-escuro, entre as máculas arredondadas superiores e inferiores. Metade inferior da margem externa da asa castanho-escura.

Genitália masculina. Comprimento das valvas duas vezes a largura (Fig. 32); extremidade distal das valvas arredondada, um pouco dilatada em clava, com dentes voltados para o lado interno (Fig. 27); unco afilado na base e alargado na metade distal (Fig. 26).

Material examinado (42 machos e 38 fêmeas), excluindo o holótipo, os demais exemplares citados são parátipos. BRASIL, São Paulo: Campos do Jordão (Umuarama, 1800m), Gagarin leg., DZ 3850, 3-15-II-1937, holótipo macho (UFPR); 1700m, D'Almeida leg. no. 5393, 5394, 5395, 5396, 31-I-1938 4 machos (UFPR); 1800m, Gagarin leg., 3-15-II-1937 4 machos e 1 fêmea, 3-II-1937 1 fêmea, 7-II-1937 1 fềmea, 9-II-1937 1 fềmea, 8-15-III-1937 5 machos e 2 fêmeas (UFPR); Campos do Jordão (Toriba, 1800m), Gagarin leg., 11 -II-1951 1 macho, 23-II-1951 1 fêmea, 17-II-1954 1 fềmea, 9-II-1951 1 macho (UFPR); Campos do Jordão (1950m), Mielke, Brown \& Laroca leg., 10-XI-1968 5 fêmeas (UFPR); (1700m), Ebert leg., no. 153 I-1966 1 macho, no. 154, 155, 157 I-1966 3 fêmea, no. 301 28-I-1966 1 fêmea (UFPR); (1600-2000m), Mielke \& Casagrande leg., 8-12-II19822 fêmeas (UFPR); (1700m), Ebert leg., 27-I-1966, no. 2512, 2513, 2 machos (UFPR); Richard Frey leg., II-1957 1 macho (UFPR); no. 56104, 1 fêmea (MZSP); 21-II-1994 1 macho (UFSCAR); 11-II-1986 2 fêmeas, 10-II-1968 1 macho e 1 fêmea (UNICAMP); Serra da Bocaina (1750m), Ebert leg., no. 159 2-III-1966 1 macho (UFPR); (1550m), Ebert leg., no. 1309 2-4-III-1967 1 fêmea (UFPR). Rio de Janeiro: Itatiaia (1500m), Mielke leg., 21-I-1969 1 fêmea (UFSCAR); 21-I-1967 2 machos e 1 fêmea, 3-II-1967 1 macho, 20-I-1969 3 machos (UNICAMP); 3-II-1967 1 macho, 20-I-1969 1 fêmea (UFSCAR); (1300-1700m), Mielke \& Brown leg., 21-I-1969 3 fêmeas (UFPR); (2000m), Mielke \& Brown leg., 21-I-1969 1 macho e 1 fêmea (UFPR); (2400m), Mielke \& Brown leg., 21-I-1969 1 macho (UFSCAR); Gagarin leg., 6-II-1937, 10-II-1937 2 fêmeas (UFPR); (2000m) O.-C. Mielke leg., 16-II-1979 1 macho, 2 fềmeas (UFPR); 2000m, Ebert leg., no. 201 II/1966 1 macho (UFPR); (2000m), Ebert leg., no. 1308 16-I-1969 1 macho (UFPR); (1400m), Ebert leg., no. 160 20-XII-1957 1 macho (UFPR); (1300m), Mielke leg., 8-I-1973 1 macho (UFPR); (1600m), Mielke leg., 12-I-1973 1 macho (UFPR); (1500m) Mielke leg., 21-I-1969 1 fềmea (UFPR); (2000m), Ebert leg., DZ3852 II-1960 1 macho, no. 1306, DZ3849 10-I-1969 1 macho, no. 1307 16-I-1969 1 macho (UFPR); Itatiaia (Agulhas Negras, $1800 \mathrm{~m}$ ), Mielke \& Casagrande leg., 17-II-1984 1 macho (UFPR); Teresópolis (1500m), Ebert leg., no. 1310 26-II-1962 1 macho (UFPR). Minas Gerais: Camanducaia (Monteverde, 1650m), Ebert leg., no. 1311 8-III-1971 1 fêmea (UFPR). 


\section{DISCUSSÃO}

Carminda paeon e C. umuarama apresentam alguns aspectos em comum: asa anterior, face inferior, com faixa marginal larga (em alguns exemplares de $C$. paeon essa faixa é estreita, porém, sempre difusa do lado interno e mais larga que a linha submarginal); asa posterior, face superior, com pequena área esbranquiçada na margem costal, entre as bases das duas faixas transversais onduladas; na genitália masculina, extremidade distal das valvas, arredondada, com dentes voltados para o lado interno. Esses três caracteres separam essas duas espécies de $C$. griseldis, na qual são observados: asa anterior, face inferior, com linha marginal mais estreita que a faixa submarginal; asa posterior, face superior, com margem costal totalmente castanha; na genitália masculina, extremidade distal das valvas afilada e curva para dentro, muito variável quanto à disposição e forma dos dentes.

Há grande variação na coloração do lado inferior da asa posterior, em $C$. paeon e $C$. griseldis; a densidade da pontuação castanho-escura também é variável. Além da variação em cor, alguns indivíduos de C. griseldis têm as faixas onduladas transversais mais retilíneas, caráter não observado em $C$. paeon.

Carminda paeon e C. griseldis foram registradas em áreas com altitudes próximas ao nível do mar (respectivamente em Caraguatatuba, São Paulo e Joinvile, Santa Catarina), e progressivamente até altitudes em torno de 2000m (respectivamente em Itatiaia, Rio de Janeiro e Campos do Jordão, São Paulo). Carminda umuarama foi registrada sempre em maiores altitudes, desde $1300 \mathrm{~m}$ até acima de 2000m, em Itatiaia, Rio de Janeiro e Campos do Jordão, São Paulo.

AGRADECIMENTOS. Aos pesquisadores mencionados na relação das coleções estudadas, pelo acesso ao material examinado. Ao Dr. Olaf H.H. Mielke, Dra Mirna Martins Casagrande e Dr. Keith S. Brown Jr., pela valiosa contribuição no decorrer dos trabalhos.

\section{REFERÊNCIAS BIBLIOGRÁFICAS}

BRown JR., K.S. 1992. 8. Borboletas da Serra do Japi: diversidade, habitats, recursos alimentares e variação temporal, p.142-187. In: L.P.C. MoRELLATO (Ed.). História Natural da Serra do Japi. Ecologia e preservação de uma área florestal no sudeste do Brasil. Campinas, Editora Unicamp, Fapesp, $321 \mathrm{p}$.

BUTLER, A.G. 1866. A monograph of the genus Euptychia, a numerous race of butterflies belonging to the family Satyridae, with descriptions of sixty species new to science, and notes on their affinities \& c. Proc. zool. Soc. London, p.458-504.

D'ABrera, B. 1988. Butterflies of neotropical region. Part V. Nymphalidae (Conc.) \& Satyridae. Victoria, Hill House Publ., 877p.

ForsteR, W. 1964. Beiträge zur Kenntnis der Insektenfauna Boliviens XIX. Lepidoptera III, Satyridae. Veröff. Zool. Staatssamml. München 8: 51-188. Godart, J.B. 1819-(1824). Papillons In: J.B. Godart \& P. LAtreille. Encyclopédie méthodique 9. Paris, 828p.

HAYWARD, K.I. 1967. Genera et species animalium argentinorum. Bonaire, 
Guillermo Kraft Ltda, vol. 4, 447p.

KIRBY, W.F. 1871. A synonymic catalogue of diurnal Lepidoptera. London, John van Voorst, V+883p.

MielKe, C.G.C. 1994. Papilionoidea e Hesperioidea (Lepidoptera) de Curitiba e seus arredores, Paraná, Brasil, com notas taxonômicas sobre Hesperiidae. Revta bras. Zool. 11 (4): 759-776.

MiLLER, L.D. 1968. The higher classification, phylogeny and zoogeography of the

Satyridae (Lepidoptera). Mem. Amer. Ent. Soc. 24: 1-174.

Weymer, G. 1910-1912. Satyridae, p. 173-283. In: A. SeITZ (Ed.). Die

Gross-Schmetterlinge der Erde. Stuttgart, Alfred Kernen Verlag, vol. 5, 1141 p.

Recebido em 10.VI.1996; aceito em 22.V.1997. 